\title{
Mortality from Alzheimer's disease in Mexico from 1980 to 2014
}

\author{
Alfredo de Jesús Celis-De la Rosa, ${ }^{1}$ Carlos Enrique Cabrera-Pivaral, ${ }^{1}$ María Guadalupe Laura \\ Báez-Báez, ${ }^{1}$ Alfredo Celis-Orozco, ${ }^{1}$ Genaro Gabriel-Ortiz² and Marco Antonio Zavala-González ${ }^{1}$ \\ ${ }^{1}$ Universidad de Guadalajara, University Center of Health Sciences, Division of Disciplines for Health Development, Promotion and Preservation, \\ Public Health Department, Jalisco, Mexico; ${ }^{2}$ Instituto Mexicano del Seguro Social, Biomedical Research Center of the West, Jalisco, Mexico
}

\begin{abstract}
Background: Dementias are rarely considered to be a main cause of death; therefore there are only few studies on Alzheimer's mortality covering long periods. Objective: To describe mortality from Alzheimer's disease in México for the period from 1980 to 2014. Method: Cross-sectional study where, with official mortality data in Mexico according to codes 331.0 and G30, respectively, of the $9^{\text {th }}$ and $10^{\text {th }}$ revisions of the International Statistical Classification of Diseases and Related Health Problems, crude and standardized Alzheimer's disease mortality rates were obtained, both nationally and by states. Results: From almost being inexistent, deaths from Alzheimer's disease went to a rate of 65.12 per 1000 females and 43.66 per 1000 males in the 2010-2014 five-year period. Throughout the study period, the age group with highest mortality rates for this cause were those older than 80 years, with 0.29 per 100,000 population in 1980-1984 and 55.02 in 100,000 in the 2010-2014 period. The region with the highest mortality was the northwest, with rates higher than 2.28 per 100,000 population. Conclusions: Mortality from Alzheimer's disease is a public health problem in Mexico with a growing trend, especially among women and older adults. Early diagnostic measures and opportune treatment are required in primary care in order to reduce this problem.
\end{abstract}

KEY WORDS: Alzheimer's disease. Mortality. Mexico.

\section{Introduction}

Alzheimer's disease is an incurable, progressive and deadly slowly-evolving neurological disorder that affects the human brain, producing progressive memory, orientation, judgment and language loss, ${ }^{1}$ which results in behavioral changes and loss of functionality for everyday activities. ${ }^{2}$ It is the most common cause of dementia, with between 60 and $70 \%$ of cases being attributed to it, ${ }^{3}$ and with a global prevalence of $4.7 \%$ estimated among individuals older than 60 years, which is equivalent to 35.6 million affected people, with an annual incidence of 3.1 per 1000 people aged 60 to 64 to 175 per 1000 people aged 95 and more. ${ }^{4}$

In Mexico, there is heterogeneous epidemiological information on the frequency of dementias: the National Survey on Health and Aging in Mexico reports $3.3 \%$, and the National Health and Nutrition Survey $7.9 \%$, while data of the latter are recognized to be comparable to those of other studies. ${ }^{5}$ An annual incidence of 27.3 per 1000 older adults is recognized. ${ }^{6}$

Apart from the above figures, it is difficult to evaluate the independent contribution of dementias to mortality. In death certificates, they are rarely considered as the main cause of death, since those affected frequently have other comorbidities that by themselves can precipitate death. ${ }^{4}$ There are only few studies at the state ${ }^{7}$ or national ${ }^{8,9}$ level on mortality from Alzheimer's and other dementias in the course of long periods of time, none of them in the Mexican population; therefore, the present research was conducted with the purpose to describe Alzheimer's disease-related mortality in Mexico, nationwide and by state, during the1980-2014 period.

\section{Method}

Based on official federal statistics, a cross-sectional study was conducted where Alzheimer's disease mortality
Correspondence:

Marco Antonio Zavala-González

E-mail: zgma_51083@yahoo.com.mx
Date of reception: 08-03-2017

Date of acceptance: 08-03-2017

DOI://dx.doi.org/10.24875/GMM.M18000188
Gac Med Mex. 2018;154:465-469

Contents available at PubMed www.gacetamedicademexico.com 


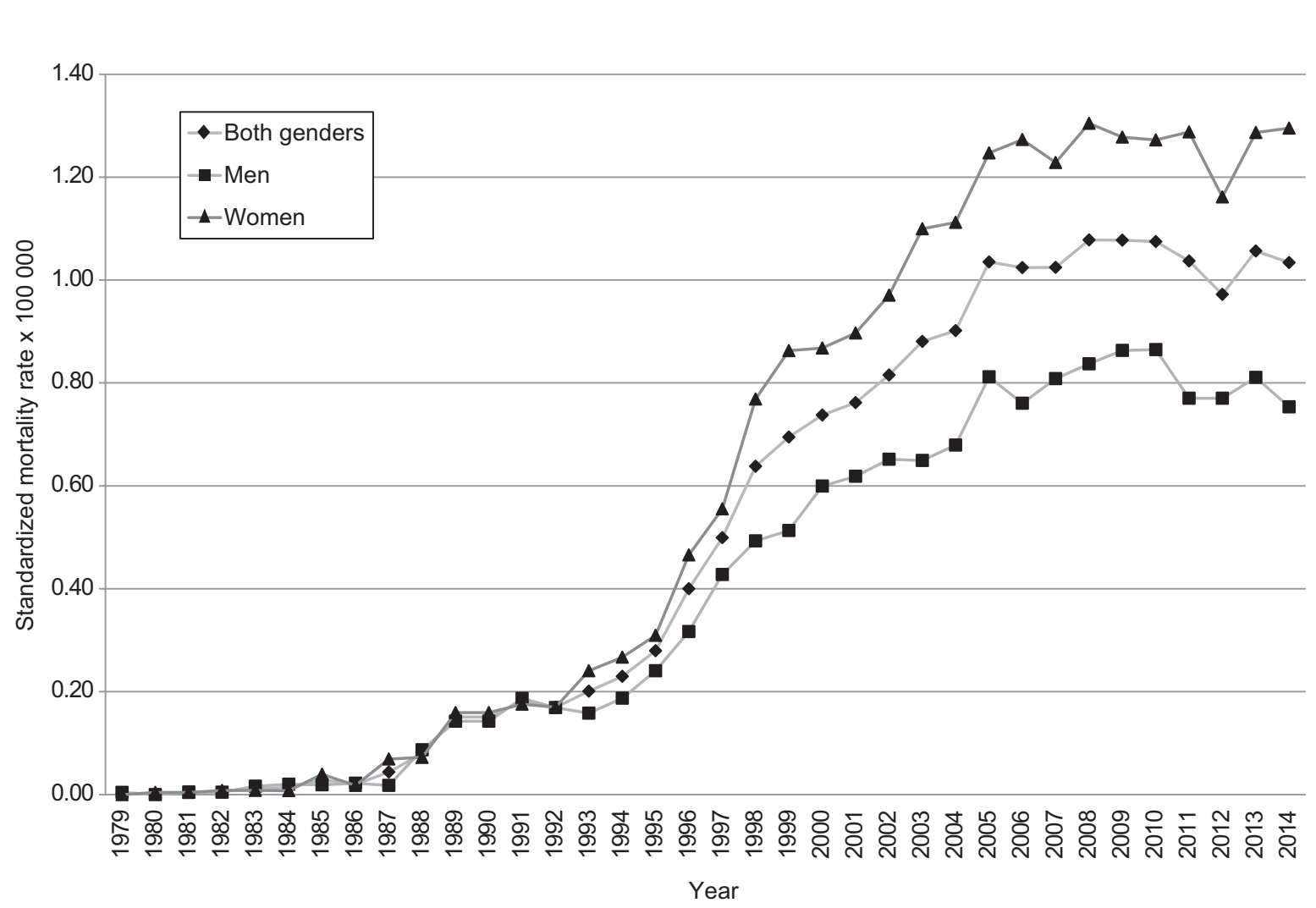

Figure 1. Annual mortality with Alzheimer's disease diagnosis in the death certificate, Mexico 1980-2014.

rates in Mexico were estimated for the 1980-2014 period. The numerators, corresponding to the number of deaths from Alzheimer's disease, were obtained from the $\mathrm{Na}$ tional Health Information System (Sinais - Sistema Nacional de Información en Salud) of Mexico, ${ }^{10}$ considering only those records with the diagnosis of interest according to the codes of the ninth and tenth revisions of the International Statistical Classification of Diseases (ICD-9, code 331.0 and ICD-10, code G30). ${ }^{11,12}$ On the other hand, the denominators, which were the number of inhabitants in Mexico according to age, gender and State, were obtained by linear projection from the population figures registered in the Population and Housing Censuses of $1980,{ }^{13} 1990,{ }^{14} 2000^{15}$ and $2010^{16}$ and in the 2015 Inter-census Survey, ${ }^{17}$ carried out by the National Institute of Statistics and Geography of Mexico. Additionally, the dementia mortality rates were obtained (ICD-9, codes 290-29411 and ICD-10, codes F00-F03) ${ }^{12}$ for the same period, in order to consider possible Alzheimer's disease misdiagnoses that could cause underestimation or overestimation since, regardless of the etiology, they share a common clinical presentation.

Standardized mortality rates were obtained according to age, gender and state per 100000 population, both annually and in 5-year periods. Age was classified in groups according to the criterion established by the
National Institute of Statistics and Geography: ${ }^{13-17}<1$ year, 1-4 years, 5-9 years, 10-19 years, 20-39 years, 40-59 years, 60-69 years, 70-79 years and 80 years or more, while the rates by state were geospatially distributed at class intervals obtained by means of Sturges rule. This analysis was carried out with Epi-Info version 7.1.5.2.

The investigation was considered free of risk according to the Mexican national legislation in force at the time the study was performed, since retrospective methods and documentary research techniques were used and no sensitive nominal information was collected from the deceased individuals. ${ }^{18}$

\section{Results}

Figure 1 shows Alzheimer's disease annualized mortality rates over the study period, where both in men and women a linear ascending trend was found in the number deaths for this cause. Figure 2 shows these rates for other dementia diagnoses during the same period, where the same tendency is observed, although less pronounced.

Table 1 shows the quinquennial mortality rates during the study period, stratified according to age and gender; an increase in mortality rates was identified at older age in both genders, especially in women. 


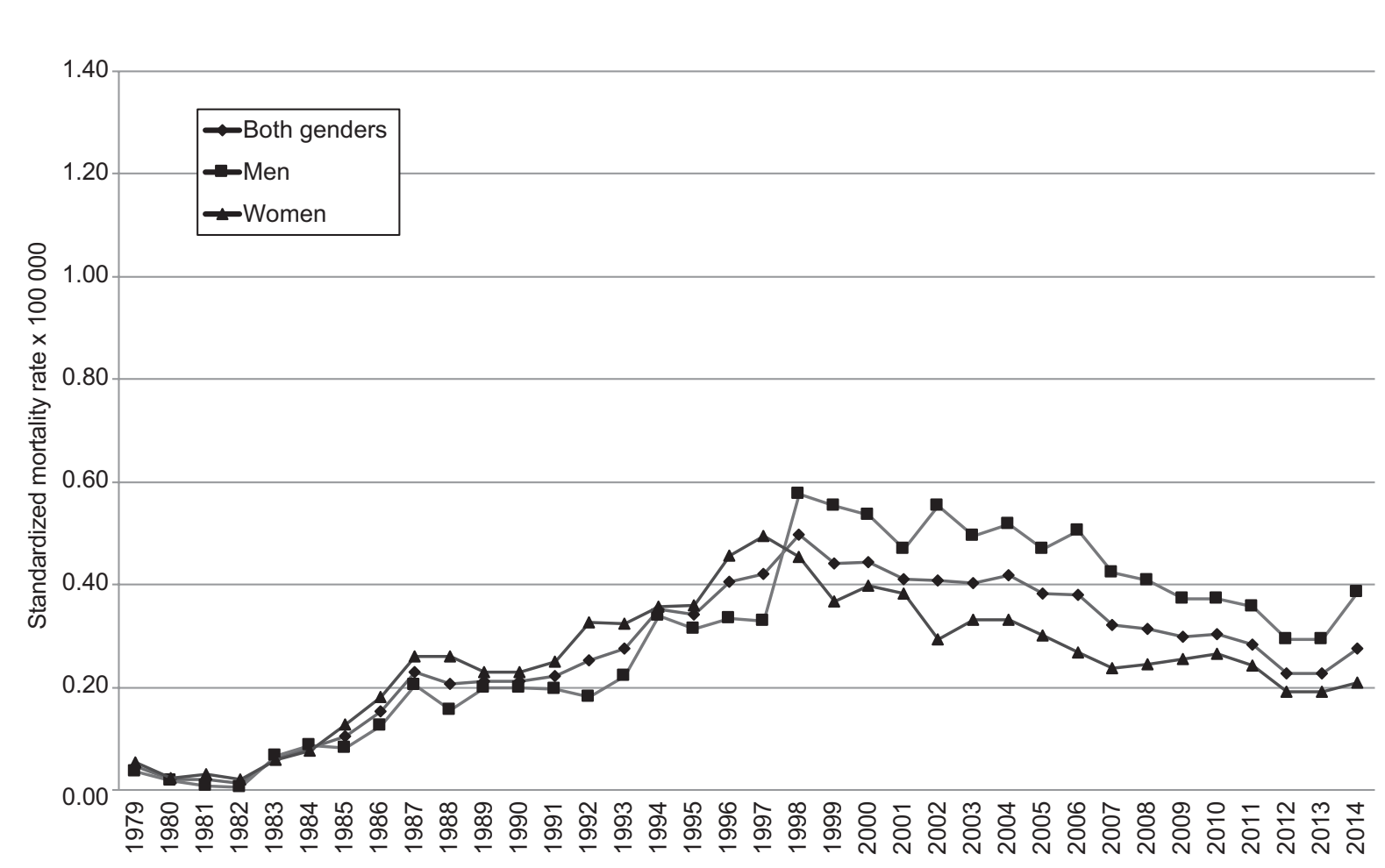

Year

Figure 2. Annual mortality with dementia diagnosis in the death certificate, Mexico 1980-2014.

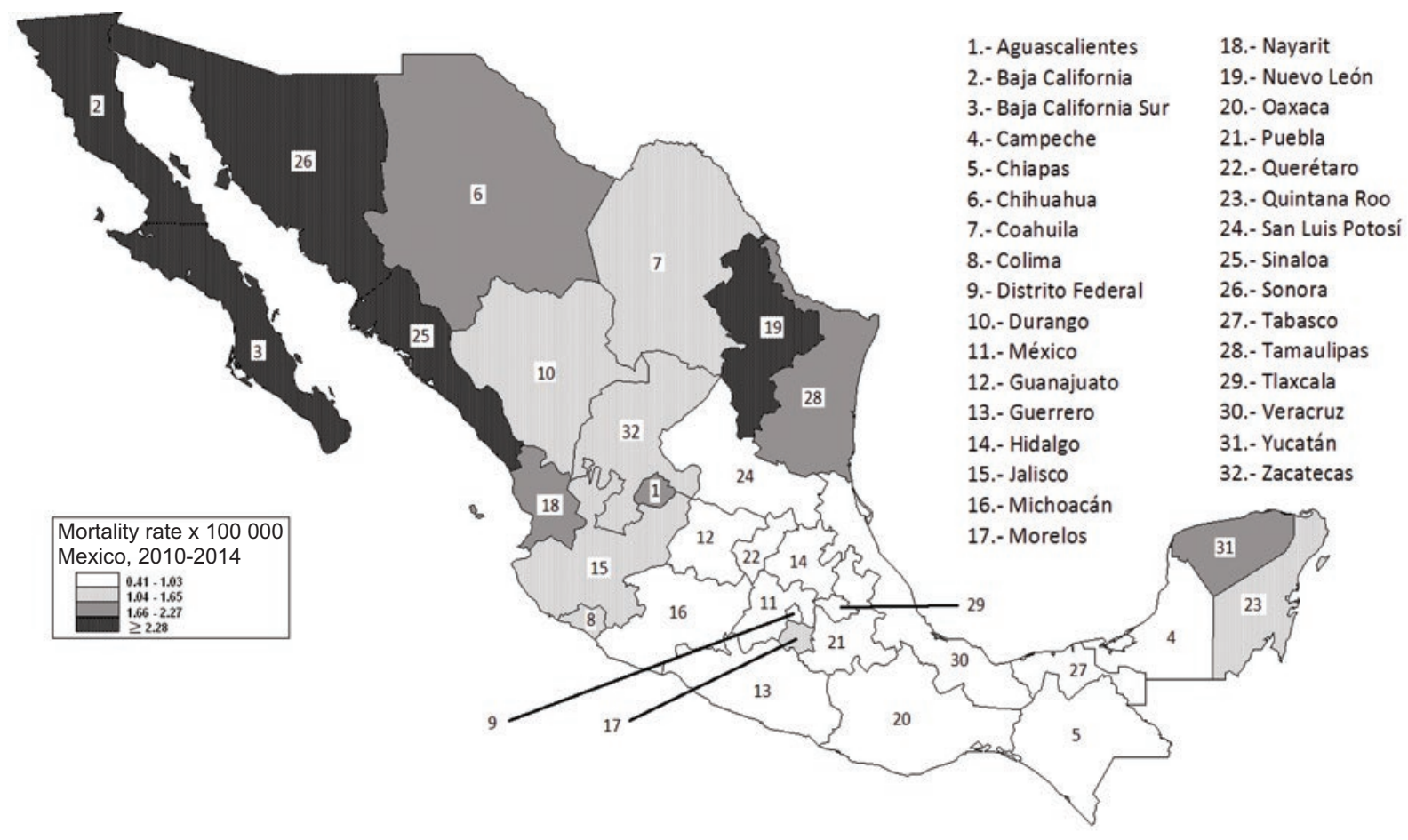

Figure 3. Alzheimer's disease global mortality in Mexico, 2010-2014, per state.

Figure 3 shows overall mortality rates during the 20102014 five-year period, stratified by state. The highest Alzheimer's disease mortality rates were found in Baja
California, Baja California Sur, Nuevo León, Sinaloa and Sonora, and the lowest in the center and south of the Mexican Republic (Morelos and Quintana Roo, respectively). 
Table 1. Alzheimer's disease quinquennial mortality in Mexico, 1980-2014, according to age and gender

\begin{tabular}{lcccc}
\hline \multirow{2}{*}{$\begin{array}{l}\text { Age } \\
\text { groups (years) }\end{array}$} & \multicolumn{3}{c}{$\begin{array}{c}\text { Standardized rates } \times 100 \\
\text { according to quinquennium }\end{array}$} \\
\cline { 2 - 5 } & $\mathbf{4}$ 1980-1984 & $\mathbf{1 9 9 0 - 1 9 9 4}$ & $\mathbf{2 0 0 0 - 2 0 0 4}$ & $\mathbf{2 0 1 0 - 2 0 1 4}$ \\
\hline Women & & & & \\
$40-59$ & 0.00 & 0.10 & 0.13 & 0.12 \\
$60-69$ & 0.02 & 0.68 & 1.84 & 1.72 \\
$70-79$ & 0.12 & 3.69 & 11.52 & 12.81 \\
$\geq 80$ & 0.13 & 7.28 & 46.38 & 65.12 \\
Men & & & & \\
$40-59$ & 0.01 & 0.08 & 0.12 & 0.11 \\
$60-69$ & 0.04 & 0.61 & 1.61 & 1.70 \\
$70-79$ & 0.03 & 2.76 & 9.52 & 10.03 \\
$\geq 80$ & 0.51 & 7.85 & 30.69 & 43.66 \\
General population & & & & \\
$40-59$ & 0.01 & 0.09 & 0.12 & 0.11 \\
$60-69$ & 0.03 & 0.64 & 1.73 & 1.69 \\
$70-79$ & 0.08 & 3.29 & 10.58 & 11.36 \\
$\geq 80$ & 0.29 & 7.53 & 39.52 & 55.02 \\
\hline
\end{tabular}

\section{Discussion}

This is the first study known to the authors where Alzheimer's disease-related mortality is described in Mexico at the national and state levels, for the longest period of time (35 years), which adds to other similar investigations in Andalusia, ${ }^{7}$ England ${ }^{8}{ }^{8}$ Wales $^{8}$ and the United States. ${ }^{9}$

In line with findings referred in the cited studies, ${ }^{7-9}$ an ascending linear trend was observed in deaths attributed to Alzheimer's disease, with predominance in the female gender, exponential growth of mortality rates from 60 years of age on and maximum occurrence in the group of 80 years and more in both genders, which might be attributed to an increase in Alzheimer's disease diagnosis over the last two decades, uneven distribution of the disease between genders, moment of disease diagnosis, uneven survival to the disease according to comorbidity, level of development of the population, increased life expectancy at birth in both genders from the decade of 1940 on, higher in women than in men, ${ }^{7-9}$ whose role and contribution to these differences should be later investigated by means of longitudinal studies.

Alzheimer's disease mortality trend is reflected at a smaller scale on deaths from other dementias, which might be attributed to the biological component of this group of diseases, which makes for them to be more common in older adults, whose number and longevity increase annually in Mexico and the world, and that might cause an increase in the diagnosis, accurate or not, of these conditions, which would have an impact on national morbidity and mortality statistics. In this tenor, appropriate classification of these diseases acquires special relevance, since it is highly likely that a significant fraction of those who died from these causes during the 35 years of the study period had had another type of dementia than that recorded as the cause of death, such as vascular, Lewy body, alcoholic or frontotemporal dementia or delirium. Hence the importance of continuous education of the medical personnel on the subject.

On the other hand, given the continuous and accelerated advance of contemporary medicine, it is possible that, eventually, other types of dementias will be identified, new diagnostic or classification criteria thereof will emerge in the short or medium term, or that new nomenclatures will be formulated, which could also increase or decrease morbidity and mortality rates attributed to these conditions, which would imply a restart in epidemiological surveillance of dementias, since retrospective redefinition of cases would be impossible based on new diagnostic criteria.

Regardless of the limitations of the present study, which are inherent to its methodological design, the results reinforce the need for a national action plan against Alzheimer's disease and other dementias in Mexico, given that current statistics reflect a large and growing number of deaths from these causes, as well as of their prevalence, as pointed out by Gutiérrez-Robledo et al. ${ }^{5,6}$

The Mexico 2014 Alzheimer and Other Dementias Action Plan, which is the result of the consensus of multiple national experts, proposes mental health prevention and promotion strategies, assurance of access to quality health services, diagnosis and timely treatment for people affected by this disease, training of human specialized resources, promotion of respect for the human rights of people affected by this disease and their caregivers, an increase in research on this and other dementias, periodic evaluation of actions effectiveness and long-term care at last stages of the disease, ${ }^{5.6}$ which at the moment of this report have been poorly diffused and have not been materialized in the national health system and which should have the prevention of therapeutic fierceness added, which is specially common in the geriatric population, and the motivations of which are complex. ${ }^{19}$

It can be concluded that despite the recognized limitations of studies of this type,,$^{7-9}$ where the death certificates that feed official statistics are considered to likely be rather unreliable, ${ }^{4}$ the increasing mortality observed due to Alzheimer's disease and other dementias is a 
public health problem in Mexico that requires immediate attention, ideally, through the implementation of the plan of action proposed in recent years.,

\section{References}

1. Mestizo-Gutiérrez SL, Hernández-Aguilar ME, Rojas-Durán $F$, Manzo-Denes J, Aranda-Abreu GE. La enfermedad de Alzheimer y la diabetes mellitus. eNeurobiología. 2014;5(10):070914. Disponible en: https:// www.uv.mx/eneurobiologia/vols/2014/10/Mestizo/Mestizo5(10)070914.pdf.

2. Guía de práctica clínica. Diagnóstico y tratamiento de la demencia tipo Alzheimer. Evidencias y recomendaciones. México: Centro Nacional de Excelencia Tecnológica en Salud; 2010.

3. Demencia. Nota descriptiva. [Internet]. EE. UU.: Organización Mundial de la Salud; 2016. Disponible en http://bit.ly/1nqmcCa.

4. Demencia: una prioridad de salud pública. EE. UU.: Organización Mundial de la Salud/Alzheimer's International; 2013.

5. Plan de acción Alzheimer y otras demencias. México: Instituto Nacional de Geriatría; 2014.

6. Gutiérrez-Robledo LM, Arrieta-Cruz I. Demencias en México: la necesidad de un Plan de Acción. Gac Med Mex. 2015;151(5):667-673. Disponible en: http://www.medigraphic.com/pdfs/gaceta/gm-2015/gm155p.pdf.

7. Ruiz-Ramos M. Análisis de las principales variables determinantes de la evolución de la mortalidad por demencias en Andalucía. Rev Esp Salud Publica. 2012;86(3):219-228. Disponible en: http://scielo.isciii.es/scielo. php?script=sci_arttext\&pid=S1135-57272012000300002
8. Griffiths C, Rooney C. Trends in mortality from Alzheimer's disease, Parkinson's disease and dementia, England and Wales, 1979-2004. Health Stat Q. 2006;30:6-14

9. Alzheimer's Association. 2016 Alzheimer's Disease facts and figures. Alzheimers Dement. 2016;12(4):459-509. DOI: 10.1016/j.jalz.2016.03.001.

10. Sistema Nacional de Información en Salud. Mortalidad. [Internet]. México: Secretaría de Salud, 2015. Disponible en http://bit.ly/2jz6GXV.

11. Clasificación Estadística Internacional de Enfermedades y Problemas Relacionados con la Salud. Novena revisión. Modificación clínica. EE. UU.: Organización Panamericana de la Salud/Organización Mundial de la Salud; 1977.

12. Clasificación Estadística Internacional de Enfermedades y Problemas Relacionados con la Salud, Décima revisión. EE. UU.: Organización Panamericana de la Salud/Organización Mundial de la Salud; 1992.

13. X Censo General de Población y Vivienda 1980. México: Instituto Nacional de Estadística y Geografía; 1981.

14. XI Censo General de Población y Vivienda 1990. México: Instituto Nacional de Estadística y Geografía; 1991.

15. XII Censo General de Población y Vivienda 2000. México: Instituto Nacional de Estadística y Geografía; 2001

16. Censo de Población y Vivienda 2010. México: Instituto Nacional de Estadística y Geografía; 2011.

17. Encuesta Intercensal 2015. México: Instituto Nacional de Estadística y Geografía; 2016.

18. Reglamento de la Ley General de Salud en Materia de Investigación para la Salud. México: Diario Oficial de la Federación; 1986.

19. Covarrubias-Bermúdez MA, González-Huerta JI, Zavala-González MA. Obstinación terapéutica en pacientes geriátricos: estudio fenomenológico de experiencias de médicos en Jalisco, México. Medicina Paliativa. 2017;3:136-142. DOI: 10.1016/j.medipa.2016.10.002. 